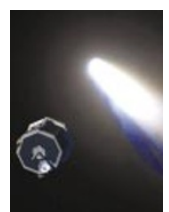

Tale of woe

NASA loses track of its comet-seeking craft p806

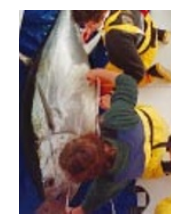

Sense of scale

Initiative launched to follow marine migration p807

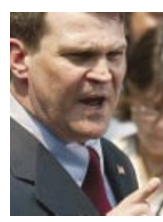

Maelstrom

Experts clash over evidence in US anthrax case p808

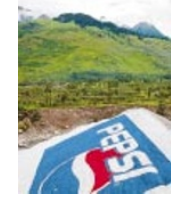

Cola wars

Rock paintings spark outcry from geologists p809

\title{
Environmental impact tops list of fears about transgenic animals
}

\section{Erika Check, Washington}

A committee convened by the US National Academy of Sciences has expressed strong concerns that transgenic animals could damage their wild surroundings.

The panel was asked by the Food and Drug Administration (FDA) to list the top scientific concerns associated with animal biotechnology. In its 21 August report, the committee put environmental concerns about the impact of genetically modified animals on natural ecosystems at the top of the list.

One US company has already produced transgenic salmon that can reach adult size three times faster than other domesticated salmon. Some scientists and environmental groups have voiced fears over the fish, saying that they could outcompete wild salmon or introduce unwanted genes into native stocks. The FDA is reviewing the fish and has not yet said whether it will allow them to be sold by the company, Aqua Bounty Farms of Waltham, Massachusetts (see Nature 406, 10-12;2000).

But the company says that it is already gathering sets of data that will meet the

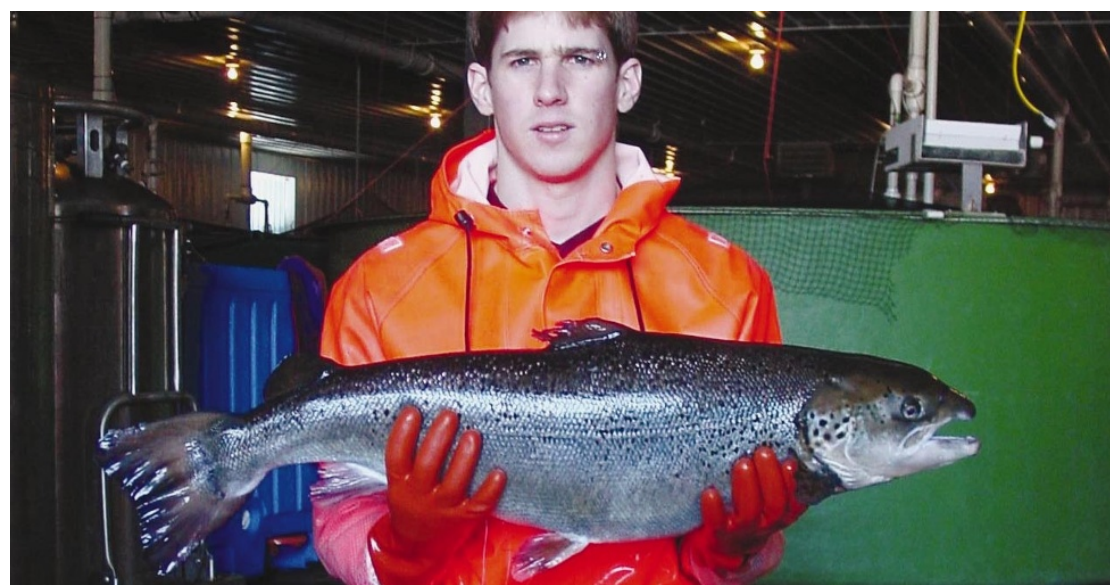

Transgenic salmon grow much faster than normal, but their impact on ecology remains unknown.

report's main concerns. "The only animal we intend to put on the market is a non-reproducing female salmon and that's intended to address an awful lot of these issues," says the firm's vice-president, Joseph McGonigle.

The academy's report says that there is not yet enough scientific evidence to prove that

\section{Public-access group plans journals}

\section{Kendall Powell, Washington}

The Public Library of Science (PLS) - a group of researchers who last year threatened to boycott scientific publishers unless they put their journals online for free - will unveil its own publishing venture by the end of the year, one of its leading members says.

Michael Eisen, a geneticist at the University of California, Berkeley, and a founding member of the PLS, says that the venture will produce free-access print and online journals, covering costs by making page charges to authors.

A year ago, the PLS withdrew its plan to initiate a boycott of established journals from 1 September 2001 - despite obtaining few concessions from publishers.

Eisen says that PubMed Central, a free archive established by the National Institutes of Health in $\mathbf{2 0 0 0}$ for access to published biomedical research, is "woefully inadequate" in meeting researchers' needs.

Ed Sequeira, who manages PubMed Central, says that retrievals from the archive have doubled in the past year to 300,000 per month. He says that it will soon add more journals to the 80 currently archived. But the Proceedings of the National Academy of Sciences has revised the time lag from its original publication to free appearance on the archive from one month to six months.

And in a setback for the concept of publicly funded research archives, the US Department of Energy says that it is considering closing its PubScience search service for physical-sciences research. transgenic salmon would be environmentally safe. There are also no definitive data on how safe the salmon — or other transgenic animals - are to eat, it notes. But the panel was less concerned about food safety as regulatory agencies already know how to remove toxic or allergenic products from the food supply.

In contrast, there is no good way to remove invasive species from their habitats if they cause problems, says panel chair John Vandenbergh, a zoologist at North Carolina State University in Raleigh. "I like to go fishing, but I don't know if I could catch all the genetically engineered salmon in the North Atlantic if they escape," he says.

In its report, the panel says that it has a "moderate level" of concern that proteins introduced into transgenic animals could cause allergic reactions if eaten by people. But it found no evidence that food products from cloned livestock - such as milk from cows - would prove dangerous.

Biotechnology companies that produce transgenic farm animals say that they hope the report will calm their investors. But environmental groups hailed the report as a critique of current US regulations on transgenics. "This backs up our contention that federal agencies aren't able to fully address the environmental and safety issues associated with these technologies," says Joe Mendelson of the Washington-based Center for Food Safety. 